\title{
PENERAPAN BALANCED SCORE CARD PADA INDUSTRI MANUFAKTUR DI INDONESIA
}

\author{
Toto Kurniawan \\ Ririn Breliastiti \\ Universitas Bunda Mulia \\ rbreliastiti@bundamulia.ac.id
}

\begin{abstract}
In order to face a competitive business environment, companies need to implement new strategies. Each flow measurement strategies need to be determined their level of success. So that a company needs to do a performance measurement in order to measure the level of success of the company. At this time, the financial performance indicators are considered no longer sufficient as a performance measurement system of the company, because it is not considered accurate in giving an assessment of the development of the company. In addition, it is not giving a clear picture about the focus and objectives of the company in the future. So we need a new paradigm in the measurement of the performance of companies in the information age today.

This study aims to provide a discussion of the application of the Balanced Scorecard in the manufacturing industry in Indonesia. Given this example is expected that many companies in Indonesia which eventually attracted and can also take benefit. Researchers establish a manufacturing company as a research subject with the consideration that the manufacturing company has the scope of the most complex operations when compared with service companies and trade. Research on the application of balanced scorecard will be conducted in three selected manufacturing companies, namely PT Cahaya Harapan Satya Printing, CV Global Mandiri and PT Tanindo Sukses Makmur.

The three companies have a Balanced Scorecard approach is a bit different, but still using the same four perspectives. Determination of the weight and the score is determined by the company taking into account the targets to be achieved for each perspective. The indicators used for each perspective also vary, depending on the target to be achieved, and the types of indicators can also vary. The three companies produce varying value Balanced Scorecard. For PT Cahaya Harapan Satya CV Printing and Global Mandiri has demonstrated good performance, but for PT Sukses Makmur Tanindo has not shown good performance. For PT Cahaya Harapan Satya CV Printing and Global Mandiri, this performance can be maintained. As for PT Sukses Makmur Tanindo performance should soon be upgraded to the condition with the category A, which is healthy.
\end{abstract}

Keywords: Balanced Scorecard, manufacture, key performance indicator

\section{PENDAHULUAN}

\subsection{Latar Belakang Masalah}


Di era informasi dan komunikasi saat ini, kita dihadapkan pada perkembangan dunia yang bergerak begitu cepat. Terutama dalam hal perekonomian, segala sesuatu diharuskan mengikuti perubahan yang sedang terjadi. Perubahan tersebut harus diantisipasi untuk menghadapi persaingan bisnis, yang dimana terjadinya suatu perdagangan bebas. Sehingga tidak ada lagi batas perdagangan antar Negara dan juga keberhasilan suatu perdagangan tergantung oleh kekuatan pasar. Oleh karena itu banyak perusahaan yang sedang melakukan adaptasi dalam struktur serta sistem organisasi yang sesuai dengan perubahan-perubahan yang sedang terjadi. Sehinga banyak perusahaan yang besaing dalam hal efisiensi, inovatif, penetapan harga, pengembangan usaha dan sebagainya.

Selama ini sistem pengukuran kinerja tradisional perusahaan dilihat dari segi finansialnya saja yang menggunakan indikator keuangan seperti Net Profit Margin (NPM), Return on Asset (ROA) dan beberapa indikator lainnya. Pada saat ini, indikator-indikator tersebut dipandang sudah tidak memadai lagi sebagai suatu sistem pengukuran kinerja perusahaan, karena dianggap sudah tidak akurat dalam memberikan suatu penilaian terhadap perkembangan perusahaan tersebut. Selain itu, pengukuran kinerja perusahaan finansial tersebut sudah tidak memberikan gambaran yang jelas tentang fokus dan tujuan perusahaan di masa yang akan datang. Sehingga diperlukan suatu paradigma baru dalam pengukuran kinerja perusahaan di era informasi saat ini.

Untuk mengatasi masalah tentang kelemahan sistem pengukuran kinerja yang hanya fokus terhadap aspek keuangan dan mengabaikan aspek non keuangan, seperti kepuasan pelanggan, produktivitas karyawan, dan sebagainya, maka diciptakanlah sebuah model pengukuran kinerja yang tidak hanya mencangkup keuangan saja melainkan non keuangan juga, yaitu konsep Balanced Scorecard (BSC).

Penelitian ini bertujuan untuk memberikan pembahasan mengenai penerapan Balanced Scorecard pada industri manufaktur di Indonesia. Dengan adanya contoh ini diharapkan banyak perusahaan di 
Indonesia yang akhirnya tertarik dan dapat juga memperoleh manfaat.

\subsection{Batasan Masalah}

Jenis usaha sangatlah beragam. Namun secara umum dapat dikelompokkan dalam tiga katagori yaitu perusahaan jasa, dagang dan manufaktur. Penelitian ini akan membahas khusus pada perusahaan manufaktur, yaitu percetakan, pabrik pelapis kayu dan pabrik boks karton.

\subsection{Perumusan Masalah}

a. Bagaimanakah kinerja perusahaan bila diukur dengan menggunakan perspektif keuangan?

b. Bagaimanakah kinerja perusahaan bila diukur dengan menggunakan perspektif pelanggan?

c. Bagaimanakah kinerja perusahaan bila diukur dengan menggunakan perspektif proses bisnis internal?

d. Bagaimanakah kinerja perusahaan bila diukur dengan menggunakan perspektif pembelajaranpertumbuhan? e. Bagaimanakah kesimpulan dari nilai Balanced Scorecard dari ketiga perusahaan?

\section{Tinjauan Pustaka}

\subsection{Pengertian}

Akuntansi

\section{Manajemen}

Menurut Hansen \& Mowen (2009a), Akuntansi manajemen merupakan proses mengidentifikasi, mengumpulkan, mengukur, mengklasifikasi dan melaporkan informasi yang bermanfaat bagi pengguna internal dalam merencanakan, mengendalikan dan mengambil keputusan. Sedangkan menurut Reeve (2009), Akuntansi Manajemen menggunakan akuntansi keuangan maupun data estimasi untuk membantu manajemen dalam menjalankan aktivitas operasional harian dan merencanakan aktivitas operasional di masa depan.

\subsection{Pengukuran Kinerja}

Menurut Halim (2009) Pengukuran Kinerja adalah suatu proses yang digunakan pimpinan untuk 
menentukan apakah seorang karyawan melakukan pekerjaannya sesuai dengan tugas dan tanggung jawabnya. Sedangkan Hansen dan Mowen (2009b) berpendapat bahwa Pengukuran Kinerja merupakan proses untuk mengukur prestasi kerja pegawai berdasarkan peraturan yang telah ditetapkan, dengan cara membandingkan sasaran (hasil kerjanya) dengan persyaratan deskripsi pekerjaan yaitu standar pekerjaan yang telah ditetapkan selama periode tertentu.

Menurut Robert \& Anthony (2012), tujuan dari sistem pengukuran kinerja adalah untuk membantu dalam menetapkan strategi. Dalam penerapan sistem pengukuran kinerja terdapat empat konsep dasar:

1. Menentukan strategi

Dalam hal ini paling penting adalah tujuan dan target organisasi dinyatakan secara ekspilit dan jelas. Strategi harus dibuat pertama kali untuk keseluruhan organisasi dan kemudian dikembangkan ke level fungsional dibawahnya.

2. Menentukan pengukuran strategi
Pengukuran strategi diperlukan untuk mengartikulasikan strategi ke seluruh anggota organisasi. Organisasi tersebut harus fokus pada beberapa pengukuran kritikal saja. Sehingga manajemen tidak terlalu banyak melakukan pengukuran indikator kinerja yang tidak perlu.

3. Mengintegrasikan pengukuran ke dalam sistem manajemen Pengukuran harus merupakan bagian organisasi baik secara formal maupun informal, juga merupakan bagian dari budaya perusahaan dan sumber daya manusia perusahaan.

4. Mengevaluasi pengukuran hasil secara berkesinambungan Manajemen harus selalu mengevaluasi pengukuran kinerja organisasi apakah masih valid untuk ditetapkan dari waktu ke waktu.

\subsection{Pengertian Balanced Scorecard}

Menurut Rangkuti (2013) Balanced Scorecard adalah kartu skor yang digunakan untuk mengukur kinerja dengan memperhatikan keseimbangan antara sisi keuangan dengan nonkeuangan, antara jangka 
pendek dan jangka panjang serta melibatkan faktor internal dan eksternal. Menurut Atkinson, Banker dan Young (Freddy Rangkuti, 2013) definisi Balanced Scorecard adalah ukuran dan sistem manajemen yang memandang kinerja suatu unit bisnis dari empat perspektif: keuangan, pelanggan, proses bisnis internal serta pembelajaran dan pertumbuhan.

\subsection{Manfaat dan Keunggulan \\ Balanced Scorecard}

Menurut Gaspersz (2013), paling sedikit terdapat enam alasan yang mendasar mengapa organisasiorganisasi lokal maupun kelas dunia memilih Balanced Scorecard sebagai kerangka kerja dari sistem manajemen mereka:

a. Balanced Scorecard mampu mengidentifikasi kekuatankekuatan dan kesempatankesempatan untuk perbaikan (opportunities for improvement $=\mathrm{OFI}$.

b. Balanced Scorecard memberikan kerangka kerja untuk peningkatan menuju keunggulan kinerja melalui memberikan peningkatan kebebasan kepada manajemen untuk

melaksanakan strategistrategi bisnis mandiri dan program-program peningkatan keunggulan kerja.

c. Balanced Scorecard merupakan kerangka kerja manajemen terintegrasi, mencakup semua faktor yang mendefinisikan organisasi, proses-proses operasional, dan hasil-hasil kinerja yang jelas dan terukur.

d. Balanced Scorecard berfokus pada persyaratan-persyaratan untuk mencapai keunggulan kinerja, bukan sekedar aplikasi prosedur-prosedur, alat-alat atau teknik-teknik.

e. Balanced Scorecard mudah beradaptasi dengan lingkungan bisnis, dapat diterapkan pada organisasi besar maupun kecil, organisasi lokal yang hanya beroperasi di suatu negara maupun kelas dunia yang beroperasi di banyak negara.

f. Balanced Scorecard telah terbukti merupakan praktekpraktek manajemen global 
yang valid untuk meningkatkan keunggulan kinerja organisasi.

\subsection{Empat Perspektif Balanced}

\section{Scorecard}

Menurut Suprayitno (2011),

Balanced Scorecard menyarankan

Gambar 1

\section{Empat Perspektif Balanced}

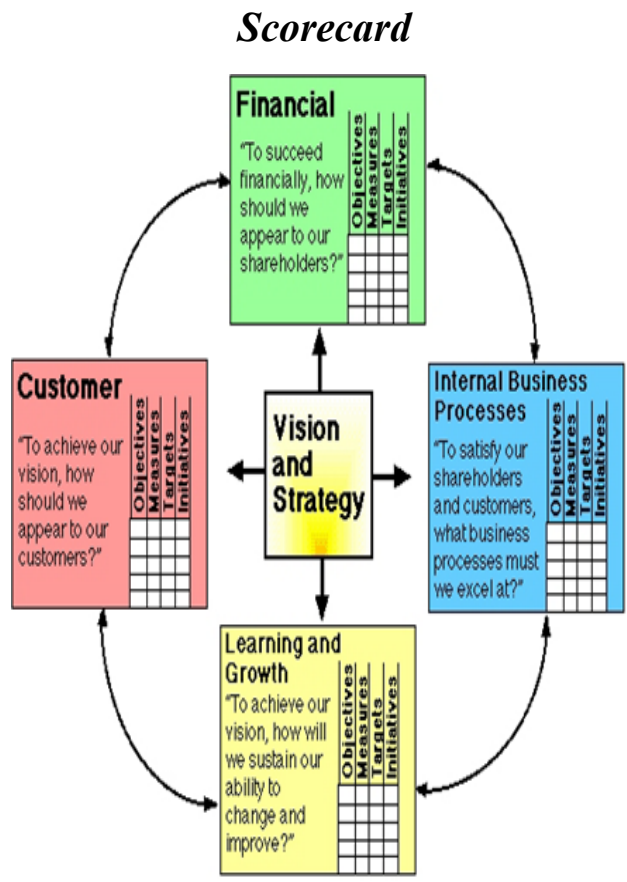

Sumber:

http://www.jiscinfonet.ac.uk/infokits/ analytical-tools/scorecard

\section{Learning and Growth}

Perspective. Kategori-kategori yang terdapat dalam perspektif ini teridiri atas kemampuan karyawan; kemampuan sistem bahwa kita melihat suatu kinerja organisasi dari empat perspektif berikut:

informasi; dan motivasi, pemberdayaan, serta kesesuaian dengan standard kinerja. Ukuran intinya adalah produktivitas karyawan, yang diukur dari: jumlah output tiap karyawan, tingkat kepuasan karyawan, tinggi rendahnya pengakuan terhadap prestasi karyawan, tingkat keterlibatan karyawan dalam proses pengambilan keputusan, kemudahan akses karyawan terhadap informasi yang menunjang pekerjaannya, dan tingkat retensi atau penolakan karyawan, yang diukur dari jumlah perputaran (turn over) staf atau karyawan potensial.

\section{Internal-Business-Process}

Perspective. Dalam perspektif internal-business-process, manajer mengenali proses-proses kritis pada yang mana mereka harus unggul jika mereka akan 
mencapai tujuan-tujuan dari shareholder dan segmen pelanggan yang menjadi target. Sistem pengukuran performa konvensional berfokus hanya pada monitoring dan peningkatan biaya, mutu, dan waktu yang didasarkan pada proses bisnis yang ada. Secara jelas, pendekatan dari Balanced Scorecard memungkinkan permintaan untuk performans proses internal untuk menurunkan harapan-haran khusus dari pihak eksternal perusahaan.

3. Customer Perspective. Perspektif Pelanggan ini menggambarkan tampilan perusahaan di mata pelanggan. Hal ini merupakan konsekuensi dari tingkat persaingan usaha yang makin ketat, sehingga perusahaan dituntut memahami kebutuhan pelanggannya (customer driven company) Ukuran utama dari perspektif pelanggan adalah market share, customer acquisition, customer retention, customer satisfaction, dan customer profitability. Kelima buah ukuran ini tidaklah terpisah- pisah, melainkan memiliki saling berhubungan.

4. Financial Perspective. Tujuan finansial menyajikan suatu fokus untuk tujuan dan ukuran dalam seluruh perspektif Balanced Scorecard. Setiap ukuran dipilih harus menjadi bagian dari suatu hubungan sebab-akibat yang memuncak dalam peningkatan performans keuangan. Balanced Scorecard harus menguraikan tentang strategi, dimulai dengan tujuan finansial jangka panjang, dan kemudian keterkaitannya terhadap bagian-bagian tindakan yang harus diambil dengan proses finansial, pelanggan, internal proses, dan terakhir karyawan dan sistem untuk mengantarkan performans ekonomis jangka panjang yang diharapkan. Walaupun bergantung pada daur hidup industrinya, tujuan strategi perspektif keuangan pada umumnya terkait pada upaya: peningkatan pendapatan, pengurangan biaya atau peningkatan produktivitas, dan utilisasi aset perusahaan. 


\section{Metode Penelitian}

Penelitian ini merupakan penelitian deskriptif berdasarkan observasi yang dilakukan pada tiga perusahaan manufaktur di Indonesia.

Peneliti menetapkan perusahaan manufaktur sebagai subjek penelitian dengan pertimbangan bahwa perusahaan manufaktur memiliki ruang lingkup operasi yang paling kompleks bila dibandingkan dengan perusahaan jasa dan dagang. Penelitian mengenai penerapan balanced scorecard ini akan dilakukan pada tiga perusahaan manufaktur terpilih, yaitu PT Cahaya Harapan Satya Printing, CV Global Mandiri dan PT Tanindo Sukses Makmur.

Teknik yang digunakan penulis dalam penelitian ini adalah sebagai berikut:

a. Pengumpulan data melalui penilaian kepustakaan (Library Research) dilakukan dengan mengkaji buku, situs web, majalah dan jurnal ilmiah untuk memperoleh landasan teoritis yang kuat dan menyeluruh tentang Balanced Scorecard. b. Telaah dokumen yaitu mengumpulkan informasi data dengan mempelajari referensi, laporan keuangan perusahaan, maupun yang berkaitan dengan masalah yang diteliti.

c. Penelitian lapangan yaitu mengumpulkan data primer, dengan cara mendatangi perusahaan.

\section{Hasil dan Pembahasan}

\subsection{PT Cahaya Harapan Satya}

\section{Printing}

PT. Cahaya Harapan Satya Printing berusaha dalam bidang percetakan. Untuk mencapai maksud dan tujuan, perseroan melaksanakan kegiatan usaha sebagai berikut: memberdayakan hasil-hasil dari penerbitan, penjilidan, katonage dan pengepakan, pencetakan buku-buku serta kegiatan terkait. Desain dan cetak grafis meliputi pembuatan desain untuk gambar-gambar, simbol, logo, keperluan pribadi maupun perusahaan dan juga kegiatan-kegiatan penting (kegiatan nasional maupun international) serta pekerjaan pencetakan majalahmajalah dan tabloid (media masa) lainnya yang terkait. 


\section{Perspektif Keuangan}

Pada perspektif keuangan, penulis menggunakan data dari laporan posisi keuangan dan laporan laba rugi selama dua periode, yaitu 20142015. Perspektif keuangan ini dapat diukur menggunakan rasio likuiditas, solvabilitas, profitabilitas, dan aktivitas.

Tabel 4.1

Kinerja Keuangan PT Cahaya Harapan Satya Printing

\begin{tabular}{ccc}
\hline Macam Rasio & 2015 & 2014 \\
\hline Rasio Likuiditas: & $153 \%$ & $157 \%$ \\
Rasio Lancar & $140 \%$ & $130 \%$ \\
\hline $\begin{array}{l}\text { Rasio Solvabilitas: } \\
\text { Rasio Utang atas Modal }\end{array}$ & $58 \%$ & $56 \%$ \\
Rasio Utang atas Aktiva & & \\
\hline Rasio Profitabilitas: & $4,23 \%$ & $3,79 \%$ \\
Profit Margin & & \\
\end{tabular}

Berdasarkan data diatas, dapat diketahui bahwa pada rasio utang atas modal mengalami peningkatan sebesar $10 \%$ yang menandakan bahwa total hutang perusahaan meningkat. Dari hasil wawancara dapat diketahui bahwa peningkatan tersebut terjadi karena perusahaan melakukan pinjaman modal kepada pihak bank guna menambah modal operasional perusahaan.

\section{Perspektif Pelanggan}

Pada perspektif pelanggan, perusahaan mengukur jumlah pelanggan yang dapat di pertahankan, jumlah klaim, jumlah pelanggan baru dengan menggunakan data yang diberikan oleh perusahaan melalui proses wawancara dengan pihak terkait dan menggunakan kuesioner untuk memperoleh data mengenai kepuasan pelanggan. 
Tabel 4.2

\section{Data Perspektif Pelanggan PT Cahaya Harapan Satya Printing}

\begin{tabular}{cccc}
\hline Tahun & $\begin{array}{c}\text { Pelanggan } \\
\text { Tetap }\end{array}$ & $\begin{array}{c}\text { Jumlah } \\
\text { Klaim }\end{array}$ & $\begin{array}{c}\text { Pelanggan } \\
\text { Baru }\end{array}$ \\
\hline 2014 & 963 & 17 & 25 \\
\hline 2015 & 978 & 9 & 15
\end{tabular}

Berdasarkan data di atas, dapat diketahui bahwa perusahaan dapat mempertahankan pelanggan lama, namun tidak dapat mencapai target tahun lalu dalam menarik pelanggan baru di tahun 2015.
Pada perspektif proses bisnis internal, perusahaan menggunakan data tambahan produk/ jasa baru dan banyaknya produk cacat yang diperoleh dari hasil wawancara dengan pihak perusahaan.

\section{Perspektif Proses Bisnis Internal}

Tabel 4.3

\section{Data Perspektif Proses Bisnis Internal (dalam unit)}

\begin{tabular}{|c|c|c|c|c|}
\hline \multirow{3}{*}{ PT } & & & & \multirow{3}{*}{$\begin{array}{l}\text { Cahaya } \\
\text { Harapan }\end{array}$} \\
\hline & Tohum & Tambahan & Drodul $C_{0}$ & \\
\hline & 1 antur & Produk/jasa & Frouk Cacal & \\
\hline \multirow{2}{*}{ Satya } & 2014 & 0 & 2.164 .781 & Printing \\
\hline & 2015 & 1 & 1.114 .044 & \\
\hline
\end{tabular}

Berdasarkan data di atas, dapat diketahui bahwa perusahaan mengeluarkan inovasi produk yang tidak ada di tahun sebelumnya. Inovasi yang dihasilkan berupa kalender berukuran mini yang dapat diletakan pada dashboard mobil. Dan pada produk cacat mengalami penurunan yang sangat signifikan.
Hal itu disebabkan oleh adanya pengecekan kualitas mutu yang lebih ketat.

\section{Perspektif Pembelajaran-}

\section{Pertumbuhan}

Pada perspektif pembelajaranpertumbuhan, penulis menggunakan data laba bersih, jumlah karyawan 
dan menggunakan kuesioner untuk mengetahui kepuasan karyawan dalam lingkungan perusahaan.
Perspektif ini diukur menggunakan produktivitas karyawan dan kepuasan karyawan.

Tabel 4.4

\section{Data Perspektif Pembelajaran-Pertumbuhan PT Cahaya Harapan Satya Printing}

\begin{tabular}{ccc}
\hline Tahun & Penjualan & Jumlah Karyawan \\
\hline 2014 & Rp 53.246.844.440,00 & 496 \\
\hline 2015 & Rp 56.305.556.663,00 & 465 \\
\hline
\end{tabular}

Berdasarkan data di atas, dapat dilihat bahwa terjadi kenaikan laba bersih ditahun 2015 meskipun dapat dilihat bahwa jumlah karyawan mengalami penurunan. Hal tersebut

Tabel 4.5

Tabel Kriteria Skor Kinerja PT Cahaya Harapan Satya Printing 2014

\begin{tabular}{|c|c|c|c|}
\hline & & & Bobot per \\
\hline Perspektif & $\begin{array}{c}\text { Bobot per } \\
\text { perspektif } \\
\text { (a) }\end{array}$ & $\begin{array}{c}\text { Kinerja } \\
\text { (2011) } \\
\text { (b) }\end{array}$ & $\begin{array}{l}\text { perspektif } \\
\text { Kinerja } \\
(2011) \\
(\text { c) }=\text { (a) } \times(\text { (b) }\end{array}$ \\
\hline Keuangan & 25 & 0.87 & 21.75 \\
\hline Pelanggan & 25 & 0.76 & 19.00 \\
\hline Bisnis Internal & 25 & 0.65 & 16,25 \\
\hline $\begin{array}{l}\text { Pembelajaran dan } \\
\text { pertumbuhan }\end{array}$ & 25 & 1.03 & 25.75 \\
\hline $\begin{array}{l}\text { TOTAL SKOR } \\
\text { PERSPEKTIF }\end{array}$ & 100 & 3.31 & 82.75 \\
\hline
\end{tabular}


Total Skor Kinerja (2014) =

$\frac{\text { TotalSkorPerspektif }}{100} \times 100 \%$

$\frac{82.75}{100} \times 100 \%$

$82.75 \%$
Berdasarkan kriteria nilai akhir skor kinerja, penilaian kinerja PT Cahaya Harapan Satya pada tahun 2014 digolongkan dalam kondisi "Sangat Sehat", kategori AA dengan total skor kinerja $82.75 \%$.

Tabel 5.6

Tabel Kriteria Skor Kinerja PT Cahaya Harapan Satya Printing 2015

\begin{tabular}{|c|c|c|c|}
\hline & & & Bobot per \\
\hline Perspektif & $\begin{array}{c}\text { Bobot per } \\
\text { perspektif } \\
\text { (a) }\end{array}$ & $\begin{array}{c}\text { Kinerja } \\
\text { (2015) } \\
\text { (b) }\end{array}$ & $\begin{array}{l}\text { perspektif } \\
\text { Kinerja } \\
(2015) \\
(\text { c) }=\text { (a) } \times(\text { (b) }\end{array}$ \\
\hline Keuangan & 25 & 0.88 & 22.00 \\
\hline Pelanggan & 25 & 0.73 & 18.25 \\
\hline Bisnis Internal & 25 & 0.89 & 22.25 \\
\hline $\begin{array}{l}\text { Pembelajaran dan } \\
\text { pertumbuhan }\end{array}$ & 25 & 1.05 & 26.25 \\
\hline $\begin{array}{l}\text { TOTAL SKOR } \\
\text { PERSPEKTIF }\end{array}$ & 100 & 3.55 & 88.75 \\
\hline
\end{tabular}

Total Skor Kinerja (2015) =

$\frac{\text { TotalSkorPerspektif }}{100} \times 100 \%$

$\frac{88.75}{100} \times 100 \%$

$88.75 \%$
Berdasarkan kriteria nilai akhir skor kinerja, penilaian kinerja PT Cahaya Harapan Satya Printing pada tahun 2015 digolongkan dalam kondisi "Sangat Sehat", kategori AA dengan total skor kinerja $88.75 \%$.

Dari pengukuran perspektif keuangan belum dapat mencapai target bobot perspektif sebesar $25 \%$ 
namun terjadi peningkatan dengan memperoleh skor kinerja $21.75 \%$ pada tahun 2014 dan $22.00 \%$ pada tahun 2015. Ini dapat dilihat dari pengukuran perspektif keuangan yang terdiri dari rasio likuiditas, solvabilitas, dan profitabilitas.

Pada perspektif pelanggan belum mencapai bobot perspektif yang ditentukan sebesar $25 \%$ dimana pada tahun 2014 perusahaan hanya mendapatkan skor $19.00 \%$ dan tahun 2015 mengalami penurunan dengan mendapatkan skor $18.25 \%$. Pencapaian yang tidak sempurna ini dikarenakan PT. Cahaya Harapan Satya Printing mengalami kendala dalam meraih pelanggan baru.

Untuk perspektif proses bisnis internal perusahaan skor kinerja pada tahun 2014 masih di bawah target yang ditentukan sebesar 25\%. Persentase bobot pada tahun 2014 pencapaiannya hanya sebesar $16.25 \%$, sedangkan di tahun 2015 terjadi peningkatan menjadi $22.25 \%$. Hal ini disebabkan karena perusahaan telah melakukan variasi produk dan dapat mengurangi tingkat produk cacat di tahun 2015.

PT Cahaya Harapan Satya Printing menganggap bahwa perspektif pembelajaran-pertumbuhan adalah penting karena karyawan merupakan partner bagi perusahaan untuk mencapai tujuan perusahaan yaitu peningkatan profit. Pencapaian target tahun 2014 dan tahun 2015 pada perspektif ini sudah mencapai bobot perspektif sebesar 25\%. Pada tahun 2014 perusahaan mampu mencapai skor nilai sebesar $25.75 \%$ sedangkan di tahun 2015 mengalami peningkatan. Skor nilai yang dicapai sebesar $26.25 \%$. Hal ini dikarenakan tingkat produktivitas terhadap perusahaan dinilai baik, karena setiap tahunnya satu orang karyawan ratarata dapat memberi kontribusi keuntungan yang meningkat untuk setiap tahunnya dan diharapkan dapat mencapai target laba yang ditentukan perusahaan. Selain itu, dengan adanya kepuasan dalam bekerja di perusahaan, diharapkan karyawan lebih termotivasi dalam bekerja agar tercipta keselarasan tujuan.

\subsection{Global Mandiri}

CV Global Mandiri memperkenalkan bahan baku yang ramah lingkungan untuk melapisi kayu pada furniture yang masih jarang digunakan oleh 
para pengusaha di bidang furnitur, yang terbuat dari resin, penolin, kraft yaitu HPL (High Pressure paper, dan decoratif paper. Laminate). HPL merupakan bahan Perusahaan menjualkan HPL dengan pelapis furnitur dan juga salah satu merk Haveel.

alternatif untuk finishing material

Tabel 4.15

Hasil Pengukuran 4 Perspektif tahun 2014

\begin{tabular}{|c|c|c|c|c|c|}
\hline Perspektif & Pengukuran & Metode Perhitungan & Nilai & Bobot & $\mathbf{N} \times \mathbf{B}$ \\
\hline \multirow{4}{*}{$\begin{array}{l}\text { Perspektif } \\
\text { keuangan }\end{array}$} & Tingkat Investasi & $\mathrm{ROA}$ & 5 & $7,5 \%$ & 0,37 \\
\hline & Tingkat Margin & NPM & 4 & $6,5 \%$ & 0,26 \\
\hline & Tingkat Kontribusi Asset & TATO & 5 & $5 \%$ & 0,25 \\
\hline & Perputaran Persediaan & Inventory Turnover & 4 & $6 \%$ & 0,24 \\
\hline \multirow{5}{*}{$\begin{array}{l}\text { Perspektif } \\
\text { Pelanggan }\end{array}$} & Customer Retention & Persentase & & & \\
\hline & & tetap. & 4 & $8 \%$ & 0,32 \\
\hline & Customer Aquisiton & Persentase pertumbuhan & & & \\
\hline & & pelanggan. & 4 & $8 \%$ & 0,32 \\
\hline & Customer Satisfaction & Index kepuasan pelanggan & 3 & $9 \%$ & 0,27 \\
\hline \multirow{4}{*}{$\begin{array}{c}\text { Perspektif } \\
\text { Bisnis } \\
\text { Internal }\end{array}$} & Sistem Informasi Internal & Kesalahan & & & \\
\hline & & Barang. & 4 & $12,5 \%$ & 0,5 \\
\hline & Ketepatan Waktu Proses & Mengukur dari PO s/d & & & \\
\hline & & Siap diantar atau diambil & 3 & $12,5 \%$ & 0,37 \\
\hline \multirow{3}{*}{$\begin{array}{c}\text { Perspektif } \\
\text { Pembelajaran } \\
\text { dan }\end{array}$} & Perputaran Karyawan & perputaran & 4 & $7,5 \%$ & 0,3 \\
\hline & & karyawan. & & & \\
\hline & Produktivitas karyawan & Tingkat produktivitas & 4 & $7,5 \%$ & 0,3 \\
\hline Pertumbuhan & Kepuasan karyawan & Index kepuasan karyawan & 4 & $10 \%$ & 0,4 \\
\hline \multicolumn{3}{|c|}{ Total nilai Balanced Scorecard tahun 2014} & & & 3,9 \\
\hline
\end{tabular}

Tabel 4.16

Hasil Pengukuran 4 Perspektif Balanced Scorecard Tahun 2015

\begin{tabular}{llllll}
\hline Perspektif & Pengukuran & Perhitungan & Nilai & Bobot & N x B \\
\hline
\end{tabular}




\begin{tabular}{|c|c|c|c|c|c|}
\hline \multirow{5}{*}{$\begin{array}{l}\text { Perspektif } \\
\text { keuangan }\end{array}$} & Tingkat Investasi & ROA & 3 & $7,5 \%$ & 0,23 \\
\hline & Tingkat Margin & NPM & 2 & $6,5 \%$ & 0,13 \\
\hline & Tingkat Kontribusi Asset & TATO & 5 & $5 \%$ & 0,25 \\
\hline & Perputaran & & & & \\
\hline & Persediaan & Inventory Turnover & 4 & $6 \%$ & 0,24 \\
\hline \multirow{6}{*}{$\begin{array}{l}\text { Perspektif } \\
\text { Pelanggan }\end{array}$} & Customer Retention & Persentase pelanggan & & & \\
\hline & & tetap. & 5 & $8 \%$ & 0,4 \\
\hline & Customer Aquisiton & Persentase pertumbuhan & & & \\
\hline & & pelanggan. & 4 & $8 \%$ & 0,32 \\
\hline & Customer Satisfaction & kepuasan & & & \\
\hline & & pelanggan & 3 & $9 \%$ & 0,27 \\
\hline \multirow{3}{*}{$\begin{array}{c}\text { Perspektif } \\
\text { Bisnis } \\
\text { Internal }\end{array}$} & Sistem Informasi Internal & Kesalahan Pengiriman & & & \\
\hline & & & 5 & $12,5 \%$ & 0,62 \\
\hline & Ketepatan Waktu Proses & $\begin{array}{l}\text { Mengukur dari PO s/d } \\
\text { Siap diantar atau diambil }\end{array}$ & 3 & $12,5 \%$ & 0,37 \\
\hline \multirow{5}{*}{$\begin{array}{c}\text { Perspektif } \\
\text { Pembelajaran } \\
\text { dan } \\
\text { Pertumbuhan }\end{array}$} & Perputaran Karyawan & Tingkat perputaran & & & \\
\hline & & karyawan. & 4 & $7,5 \%$ & 0,3 \\
\hline & Produktivitas karyawan & Tingkat produktivitas & 5 & $7,5 \%$ & 0,37 \\
\hline & Kepuasan karyawan & Index kepuasan & & & \\
\hline & & karyawan & 4 & $10 \%$ & 0,4 \\
\hline \multicolumn{5}{|c|}{ Total nilai Balanced Scorecard Tahun 2015} & 3,9 \\
\hline
\end{tabular}

Tabel 4.17

Hasil Perbandingan Balanced Scorecard Tahun 2014 dengan Tahun 2015

\begin{tabular}{clccccc}
\hline \multirow{2}{*}{ Perspektif } & \multirow{2}{*}{ Indikator } & \multicolumn{2}{c}{ Tahun 2014 } & \multicolumn{2}{c}{ Tahun 2015 } \\
\cline { 3 - 6 } & & $\mathbf{N}$ & $\mathbf{N x B}$ & $\mathbf{N}$ & $\mathbf{N x B}$ \\
\hline \multirow{2}{*}{ Perspektif } & ROA & NPM & 5 & 0,37 & 3 & 0,23 \\
Keuangan & TATO & 4 & 0,26 & 2 & 0,13 \\
& Inventory Turnover & 5 & 0,25 & 5 & 0,25 \\
& Perspektif & Persentase pelanggan tetap. & 4 & 0,24 & 4 & 0,24 \\
\hline
\end{tabular}




\begin{tabular}{clcccc}
\hline Pelanggan & Persentase pertumbuhan pelanggan. & 4 & 0,32 & 4 & 0,32 \\
& Index kepuasan pelanggan & 3 & 0,27 & 3 & 0,27 \\
\hline $\begin{array}{c}\text { Perspektif } \\
\text { Proses Bisnis } \\
\text { Internal }\end{array}$ & Kesalahan Pengiriman Barang. & 4 & 0,52 & 5 & 0,62 \\
Ketepatan waktu proses & 3 & 0,37 & 3 & 0,37 \\
$\begin{array}{c}\text { Perspektif } \\
\text { danbelajaran }\end{array}$ & Tingkat perputaran karyawan. & & & & \\
\hline Pertumbuhan & Index kepuasan karyawan & 4 & 0,3 & 4 & 0,3 \\
Total Skor & & 4 & 0,3 & 5 & 0,37 \\
\hline
\end{tabular}

Setelah menganalisis perbandingan tiap-tiap pengukuran empat perspektif dalam balanced scorecard antara tahun 2014 dengan tahun 2015 pada CV Global Mandiri Jakarta, maka telah di dapatkan skor akhir untuk masing - masing balanced scorecard yaitu untuk tahun 2014 skor nya adalah sebesar 3,9, dan untuk tahun 2015, diperoleh skor akhir sama dengan tahun 2014 yaitu 3,9. Maka kinerja CV Global Mandiri untuk kedua tahun yaitu tahun 2014 dan 2015 sama - sama BAIK yang berarti, kinerja CV Global Mandiri telah mendekati standar normal atau target perusahaan atau sedikit dibawah standar normal, namun telah menunjukkan perbaikan baik dari segi kuantitas (produktivitas, rendemen, dan sebagainya) maupun kualitas (waktu, mutu, dan sebagainya).

Walaupun dalam kinerja keuangan CV Global Mandiri di tahun 2015 sempat mengalami penurunan yang cukup signifikan pada ROA dan NPM dari tahun 2014 yang membuat skor untuk kinerja keuangan rendah, namun pada tahun 2015 hasil pengukuran untuk customer retention, tingkat kesalahan pengiriman barang dan produktivitas karyawan telah meningkat sehingga dapat menopang penurunan skor yang terjadi pada perspektif keuangan. Hal ini membuktikan bahwa kinerja keuangan tidak selalu 
menjadi patokan dalam menilai kinerja keseluruhan dalam perusahaan. Dengan adanya perspektif pelanggan, bisnis internal dan pembelajaran dan pertumbuhan membuat CV Global Mandiri dapat meningkatkan kinerja keuangannya lewat ketiga perspektif lainnya. Namun dalam hal evaluasi pada CV Global Mandiri Jakarta, masih terdapat empat hal yang harus diperhatikan agar dapat memperbaiki kinerja pada tahun berikutnya. Keempat hal tersebut adalah ROA, NPM, customer satisfaction, dan ketepatan waktu proses pesanan.

\subsection{PT Tanindo Sukses Makmur}

PT Tanindo Sukses Makmur, yaitu sebuah perusahaan yang bergerak di bidang carton box dan general supplier.

\section{Perhitungan Balanced Scorecard Tahun 2014}

Tahap 1: mengukur Bobot dan Bobot Indikator

Tabel 4.18

MENGUKUR BOBOT DAN BOBOT INDIKATOR

\begin{tabular}{|c|c|c|c|c|c|}
\hline & Perspektif & KPI dan KRI & $\begin{array}{c}\text { Jumlah } \\
\text { Indikator }\end{array}$ & Bobot & $\begin{array}{c}\text { Bobot } \\
\text { Indikator }\end{array}$ \\
\hline \multirow[t]{4}{*}{1} & Finansial & Current Ratio & \multirow{4}{*}{4} & \multirow{4}{*}{26} & \multirow{4}{*}{6,5} \\
\hline & & Quick Ratio & & & \\
\hline & & ROA & & & \\
\hline & & NPM & & & \\
\hline \multirow[t]{3}{*}{2} & Pelanggan & Customer & \multirow[b]{3}{*}{2} & \multirow[b]{3}{*}{25} & \multirow[b]{3}{*}{12,5} \\
\hline & & Retention & & & \\
\hline & & $\begin{array}{l}\text { Costemer } \\
\text { Acquisition }\end{array}$ & & & \\
\hline 3 & proses internal & $\mathrm{MCE}$ & 1 & 24 & 24 \\
\hline \multirow[t]{4}{*}{4} & pembelajaran & produktivitas & \multirow{3}{*}{2} & \multirow{3}{*}{25} & \multirow{3}{*}{12,5} \\
\hline & & karyawan & & & \\
\hline & & retensi karyawan & & & \\
\hline & \multicolumn{2}{|l|}{ Total } & \multicolumn{3}{|c|}{100} \\
\hline
\end{tabular}


Tahap 2 : Mengukur Skor Tertimbang Maksimum

Tabel 4.19

MENGUKUR SKOR TERTIMBANG MAKSIMUM

\begin{tabular}{lcccc}
\hline Perspektif & $\begin{array}{c}\text { jumlah } \\
\text { indikator }\end{array}$ & $\begin{array}{c}\text { skor indikator } \\
\text { maks }\end{array}$ & $\begin{array}{c}\text { bobot } \\
\text { indikator }\end{array}$ & $\begin{array}{c}\text { skor tertimbang } \\
\text { maks }\end{array}$ \\
\hline Finansial & 4 & 5 & 6,5 & 130 \\
\hline Pelanggan & 2 & 5 & 12,5 & 125 \\
\hline Proses & & 5 & & 120 \\
Internal & 1 & 5 & 12,5 & 125 \\
\hline Pembelajaran & 2 & & & $\mathbf{5 0 0}$ \\
\hline Total & & &
\end{tabular}

Rumus Skor Tertimbang Maksimum = Jumlah Indikator x Skor Indikator maksimum $\quad \mathrm{x}$ Bobot Indikator

Tahap 3 : Mengukur Jumlah Skor

\section{Tertimbang}

Pemberian nilai $\mathrm{A}=5, \mathrm{~B}=4, \mathrm{C}=3$, $\mathrm{D}=2$, dan $\mathrm{E}=1$ untuk masingmasing indicator adalah berdasarkan lima kriteria masing-masing indicator yaitu dengan menggunakan nilai interval kelas dan rumus.

Tabel 4.20

MENGUKUR JUMLAH SKOR TERTIMBANG

\begin{tabular}{llcc}
\hline \multicolumn{1}{c}{ Perspektif } & \multicolumn{1}{c}{ KPI } & Nilai & $\begin{array}{c}\text { Skor } \\
\text { Indikator }\end{array}$ \\
\hline Finansial & Current Ratio & $\mathrm{B}$ & 4 \\
\hline & Quick Ratio & $\mathrm{B}$ & 4 \\
\hline & ROA & $\mathrm{E}$ & 1 \\
\hline & NPM & $\mathrm{E}$ & 1 \\
\hline & Total & & $\mathbf{1 0}$ \\
\hline Pelanggan & Customer Retention & $\mathrm{A}$ & 5 \\
\hline & Costemer Acquisition & $\mathrm{D}$ & 2 \\
\hline & & & \\
\hline
\end{tabular}




\begin{tabular}{llll}
\hline Proses Internal & MCE & C & 3 \\
\hline & Total & & $\mathbf{3}$ \\
\hline Pembelajaran & produktivitas karyawan & D & 2 \\
\hline & retensi karyawan & E & 1 \\
\hline & & \\
\hline & Total & $\mathbf{3}$ \\
\hline
\end{tabular}

Tahap 4 : Mengukur Nilai Akhir per Komponen

Tabel 4.21

MENGUKUR NILAI AKHIR PER KOMPONEN

\begin{tabular}{lccc}
\hline Perspektif & $\begin{array}{c}\text { Skor Tertimbang } \\
\text { maks }\end{array}$ & Skor tertimbang & $\begin{array}{c}\text { Nilai Akhir } \\
\text { Komponen }\end{array}$ \\
\hline Finansial & 130 & 65 & $50 \%$ \\
\hline Pelanggan & 125 & 87,5 & $70 \%$ \\
\hline Proses & & & $60 \%$ \\
Internal & 120 & 72 & $30 \%$ \\
\hline Pembelajaran & 125 & 37,5 &
\end{tabular}

Rumus nilai akhir komponen $(0-100)=$ (skor tertimbang/skor tertimbang maksimum) 100

Tahap 5 : Menghitung Nilai Akhir Total atau Total Score

Tabel 4.22

MENGHITUNG NILAI AKHIR TOTAL

\begin{tabular}{lccc}
\hline Perspektif & $\begin{array}{c}\text { Jumlah Score } \\
\text { Indikator }\end{array}$ & $\begin{array}{c}\text { Bobot } \\
\text { Indikator }\end{array}$ & $\begin{array}{c}\text { Skor } \\
\text { Tertimbang }\end{array}$ \\
\hline Finansial & 10 & 6,5 & 65 \\
\hline Pelanggan & 7 & 12,5 & 87,5 \\
\hline Proses Internal & 3 & 24 & 72 \\
\hline Pembelajaran & 3 & 12,5 & 37,5 \\
\hline Jumlah Skor Tertimbang & & & $\mathbf{2 6 2}$ \\
\hline
\end{tabular}

Rumus nilai akhir total $=$ (Jumlah skor tertimbang/Jumlah skor tertimbang maksimum $) 100 \%=(262 / 500) 100 \%=\mathbf{5 2 , 4 \%}$

Selanjutnya yaitu menggunakan kriteria standar : 
Tabel 4.23

KRITERIA STANDAR PENGUKURAN BSC

\begin{tabular}{ccc}
\hline Kondisi & Kategori & Total Score \\
\hline SANGAT SEHAT & AAA & $>95$ \\
\hline AA & $80 \%<$ TS $<95 \%$ \\
\hline KURANG SEHAT & ABB & $65 \%<\mathrm{TS}<80 \%$ \\
\hline TIDAK SEHAT & BB & $50 \%<\mathrm{TS}<65 \%$ \\
\hline B & $40 \%<\mathrm{TS}<50 \%$ \\
\hline CCC & $30 \%<\mathrm{TS}<40 \%$ \\
\hline
\end{tabular}

Kesimpulan yang diperoleh adalah perusahaan dengan nilai total skor pada tahun 2014 yaitu sebesar 52,4\% bahwa perusahaan telah masuk kondisi Kurang Sehat dengan kategori BBB. Hal ini dikarenakan rendah nya perspektif keuangan dan perspektif pembelajaran dan pertumbuhan. dari perspektif keuangan yaitu hanya memiliki nilai sebesar 65 dan perspektif pembelajaran yaitu sebesar 37,5 , hal ini dikarenakan terlalu besar biaya yang dikeluarkan oleh perusahaan, sehingga pendapatan yang diperoleh menjadi rendah, hal ini mengakibatkan ROA dan NPM yang memiliki nilai rendah, sehingga perusahaan harus meningkatkan penjualan dan mengurangi biayabiaya yang tidak terlalu penting agar ROA dan NPM dapat meningkat. Sedangkan dalam perspektif pembelajaran dan pertumbuhan rendahnya perspektif ini dikarenakan rendahnya tingkat kenyaman,sarana dan prasarana yang tidak sesuai dengan keinginan karyawan sehingga banyak keluar masuknya karyawan pada PT Tanindo Sukses Makmur. Sehingga yang harus diperhatikan oleh perusahaan yaitu terus meningkatkan kenyaman, pemberian fasilitas sehingga karyawan tersebut dapat merasa senang. 


\section{Perhitungan Balanced Scorecard Untuk Tahun 2015}

Tahap 1: mengukur Bobot dan Bobot Indikator

Tabel 4.24

MENGUKUR BOBOT INDIKATOR

\begin{tabular}{|c|c|c|c|c|c|}
\hline & Perspektif & KPI dan KRI & $\begin{array}{c}\text { Jumlah } \\
\text { Indikator }\end{array}$ & Bobot & $\begin{array}{c}\text { Bobot } \\
\text { Indikator }\end{array}$ \\
\hline \multirow[t]{4}{*}{1} & Finansial & Current Ratio & \multirow{4}{*}{4} & \multirow{4}{*}{26} & \multirow{4}{*}{6,5} \\
\hline & & Quick Ratio & & & \\
\hline & & ROA & & & \\
\hline & & NPM & & & \\
\hline & \multirow[t]{6}{*}{ Pelanggan } & Customer & \multirow{6}{*}{3} & \multirow{6}{*}{25} & \multirow{6}{*}{8,3} \\
\hline & & Retention & & & \\
\hline & & Costemer & & & \\
\hline & & Acquisition & & & \\
\hline & & Costomer & & & \\
\hline & & Satisfaction & & & \\
\hline 3 & proses internal & MCE & 1 & 24 & 24 \\
\hline \multirow{5}{*}{\multicolumn{2}{|c|}{ pembelajaran }} & produktivitas & \multirow{5}{*}{3} & \multirow{5}{*}{25} & \multirow{5}{*}{8,3} \\
\hline & & karyawan & & & \\
\hline & & retensi karyawan & & & \\
\hline & & kepuasan & & & \\
\hline & & karyawan & & & \\
\hline \multicolumn{2}{|r|}{ Total } & & & 100 & \\
\hline
\end{tabular}

Tahap 2 : Mengukur Skor Tertimbang Maksimum

Tabel 4.25

MENGUKUR SKOR TERTIMBANG MAKSIMUM

\begin{tabular}{lcccc}
\hline Perspektif & $\begin{array}{c}\text { jumlah } \\
\text { indikator }\end{array}$ & $\begin{array}{c}\text { skor indikator } \\
\text { maks }\end{array}$ & $\begin{array}{c}\text { bobot } \\
\text { indikator }\end{array}$ & $\begin{array}{c}\text { skor tertimbang } \\
\text { maks }\end{array}$ \\
\hline Finansial & 4 & 5 & 6,5 & 130 \\
\hline Pelanggan & 3 & 5 & 8,3 & 124,5 \\
\hline Proses & & 5 & 24 & 120 \\
Internal & 1 & 5 & 8,3 & 124,5 \\
\hline Pembelajaran & 3 & & & $\mathbf{5 0 0}$ \\
\hline Total & & &
\end{tabular}

Rumus Skor Tertimbang Maksimum = Jumlah Indikator x Skor Indikator maksimum $\mathrm{x}$ Bobot Indikator 
Tahap 3 : Mengukur Jumlah Skor

\section{Tertimbang}

Pemberian nilai $\mathrm{A}=5, \mathrm{~B}=4, \mathrm{C}=3$, $\mathrm{D}=2$, dan $\mathrm{E}=1$ untuk masing- masing indicator adalah berdasarkan lima kriteria masing-masing indikator yaitu dengan menggunakan nilai interval kelas dan rumus.

Tabel 4.26

MENGUKUR JUMLAH SKOR TERTIMBANG

\begin{tabular}{llcc}
\hline \multicolumn{1}{c}{ Perspektif } & \multicolumn{1}{c}{ KPI } & Nilai & $\begin{array}{c}\text { Skor } \\
\text { Indikator }\end{array}$ \\
\hline Finansial & Current Ratio & $\mathrm{B}$ & 4 \\
\hline & Quick Ratio & $\mathrm{C}$ & 3 \\
\hline & ROA & $\mathrm{E}$ & 1 \\
\hline & NPM & $\mathrm{E}$ & 1 \\
\hline & Total & & $\mathbf{9}$ \\
\hline Pelanggan & Customer Retention & $\mathrm{A}$ & 5 \\
\hline & Costemer Acquisition & $\mathrm{C}$ & 3 \\
\hline & Costomer Satisfaction & $\mathrm{A}$ & 5 \\
\hline Proses Internal & Motal & & $\mathbf{1 3}$ \\
\hline & TCE & $\mathrm{C}$ & 3 \\
\hline Pembelajaran & prodal & $\mathrm{C}$ & $\mathbf{3}$ \\
\hline & retensi karyawan & $\mathrm{E}$ & 1 \\
\hline & kepuasan karyawan & $\mathrm{B}$ & 4 \\
\hline & Total & & $\mathbf{8}$ \\
\hline
\end{tabular}

Tahap 4 : Mengukur Nilai Akhir per Komponen

Tabel 4.27

MENGUKUR NILAI AKHIR PER KOMPONEN

\begin{tabular}{lccc}
\hline Perspektif & $\begin{array}{c}\text { Skor Tertimbang } \\
\text { maks }\end{array}$ & Skor tertimbang & $\begin{array}{c}\text { Nilai Akhir } \\
\text { Komponen }\end{array}$ \\
\hline Finansial & 130 & 58,5 & $45 \%$ \\
\hline Pelanggan & 124,5 & 107,9 & $86,6 \%$ \\
\hline Proses & & & \\
Internal & 120 & 72 & $60 \%$ \\
\hline Pembelajaran & 124,5 & 66,4 & $53,5 \%$ \\
\hline
\end{tabular}

Rumus nilai akhir komponen $(0-100)=$ (skor tertimbang/skor tertimbang maksimum) 100 
Tahap 5 : Menghitung Nilai Akhir Total atau Total Score

Tabel 4.28

MENGHITUNG NILAI AKHIR TOTAL

\begin{tabular}{lccc}
\hline \multicolumn{1}{c}{ Perspektif } & $\begin{array}{c}\text { Jumlah Score } \\
\text { Indikator }\end{array}$ & $\begin{array}{c}\text { Bobot } \\
\text { Indikator }\end{array}$ & $\begin{array}{c}\text { Skor } \\
\text { Tertimbang }\end{array}$ \\
\hline Finansial & 9 & 6,5 & 58,5 \\
\hline Pelanggan & 13 & 8,3 & 107,9 \\
\hline Proses Internal & 3 & 24 & 72 \\
\hline Pembelajaran & 8 & 8,3 & 66,4 \\
\hline Jumlah Skor Tertimbang & & & $\mathbf{3 0 4 , 8}$ \\
\hline
\end{tabular}

Rumus nilai akhir total $=($ Jumlah skor tertimbang/Jumlah skor tertimbang maksimum $) 100 \%=(304,8 / 500) 100 \%=\mathbf{6 0 , 9 6 \%}$

Selanjutnya yaitu menggunakan kriteria standar :

Tabel 4.28

KRITERIA STANDAR BSC

\begin{tabular}{lcc}
\hline \multicolumn{1}{c}{ Kondisi } & Kategori & Total Score \\
\hline $\begin{array}{l}\text { SANGAT } \\
\text { SEHAT }\end{array}$ & AAA & $>95 \%$ \\
\hline & AA & $80 \%<\mathrm{TS}<95 \%$ \\
\hline KURANG & $\mathrm{A}$ & $65 \%<\mathrm{TS}<80 \%$ \\
SEHAT & $\mathrm{BBB}$ & $50 \%<\mathrm{TS}<65 \%$ \\
\hline \multicolumn{2}{c}{$\mathrm{BB}$} & $40 \%<\mathrm{TS}<50 \%$ \\
\hline TIDAK SEHAT & $\mathrm{B}$ & $30 \%<\mathrm{TS}<40 \%$ \\
\hline & $\mathrm{CCC}$ & $20 \%<\mathrm{TS}<30 \%$ \\
\hline & $\mathrm{CC}$ & $10 \%<\mathrm{TS}<20 \%$ \\
\hline
\end{tabular}

Kesimpulan yang diperoleh pada tahun 2015 yaitu perusahaan dengan nilai total skor $60,96 \%$, bahwa perusahaan telah masuk kondisi Kurang Sehat dengan kategori BBB, tetapi jika dibandingakan dengan tahun sebelumnya yaitu pada tahun 2014 yang memiliki skor akhir sebesar 52,4\% bahwa dalam peningkatan skor nilai yang 
diperoleh perusahaan sudah mengalami peningkatan walaupun perusahaan masih masuk kedalam kategori BBB yang arti nya Kurang Sehat. Namun hal ini dikarenakan rendah nya perspektif keuangan dan perspektif pembelajaran dan pertumbuhan. dari perspektif keuangan yaitu hanya memiliki nilai sebesar 58 dan pembelajaran yaitu sebesar 66,4. Hal ini dikarenakan terlalu besar biaya yang dikeluarkan oleh perusahaan, sehingga pendapatan yang diperoleh menjadi rendah, dan akibatnya ROA dan NPM yang dimiliki perusahaan menjadi rendah, sehingga perusahaan harus melakukan peningkatkan penjualan dan mengurangi biayabiaya agar ROA dan NPM dapat meningkat. Sedangkan dalam perspektif pembelajaran dan pertumbuhan rendahnya perspektif ini dikarenakan rendahnya tingkat kenyaman,sarana dan prasarana yang tidak sesuai dengan keinginan karyawan sehingga banyak keluar masuknya karyawan pada PT Tanindo Sukses Makmur. Sehingga yang harus diperhatikan oleh perusahaan yaitu terus meningkatkan kenyaman, pemberian fasilitas sehingga karyawan tersebut dapat merasa nyaman dan aman bekerja di perusahaan.

\section{Simpulan}

Dari hasil analisis yang telah dilakukan, penelitian ini memberikan hasil sebagai berikut.

a. Ketiga perusahaan memiliki pendekatan Balanced Scorecard yang agak berbeda, namun tetap menggunakan empat perspektif yang sama.

b. Penetapan bobot dan skor ditentukan sendiri oleh perusahaan dengan mempertimbangkan target yang hendak dicapai untuk tiap-tiap perspektif.

c. Indikator yang digunakan untuk tiap-tiap perspektif juga bervariasi, tergantung pada target yang hendak dicapai, dan jenis indikator juga dapat berbeda-beda.

d. Ketiga perusahaan menghasilkan nilai Balanced Scorecard yang bervariasi. Untuk PT Cahaya Harapan Satya Printing dan CV Global Mandiri telah menunjukkan kinerja BSC yang baik, namun untuk PT Tanindo 
Sukses Makmur belum menunjukkan kinerja BSC yang baik. Bagi PT Cahaya Harapan Satya Printing dan CV Global Mandiri, kinerja ini dapat terus dipertahankan. Sedangkan untuk PT Tanindo Sukses Makmur kinerja BSC harus segera ditingkatkan menuju kondisi dengan kategori A, yaitu sehat.

Bagi perusahaan yang saat ini sedang mempertimbangkan untuk menggunakan Balanced Scorecard, dapat mengadaptasi salah salah satu contoh dari ketiga perusahaan yang telah dianalis. Perusahaan dapat melakukan adaptasi sesuai dengan kondisi yang dihadapi.

\section{Daftar Pustaka}

Anthony, Robert N. dan Govindarajan, Vijay (2009). Sistem Pengendalian Manajemen. Salemba Empat, Jakarta.

Gaspersz, Vincent (2013), All-in-one 150 Key Performance Indicators and Balanced Scorecard, Malcom Baldrige, Leans Six Sigma Suplly Chain Management, Tri-AlBros Publishing, Jakarta.

Halim, Abdul (2009). Sistem Pengendalian Manajemen.
Sekolah Tinggi Ilmu Manajemen YKPN. Yogyakarta.

Hansen, Don. R., Maryanne M. Mowen, (2009a), Akuntansi Manajemen, Edisi 8, Buku 1, Salemba Empat, Jakarta.

Hansen, Don. R., Maryanne M. Mowen, (2009b), Akuntansi Manajemen, Edisi 8, Buku 2, Salemba Empat, Jakarta.

Luis, Suwardi dan Biromo (2013), Step by Step in Cascading Balanced Scorecard to Functional Scorecards, PT. Gramedia Pustaka Utama, Jakarta.

Mahmudi (2013), Manajemen Kinerja Sektor Publik, Edisi 2, Sekolah Tinggi Ilmu Manajemen YKPN, Yogyakarta.

Rangkuti, Freddy (2013), SWOT Balanced Scorecard, Gramedia, Jakarta.

Reeve, James M., (2009), Pengantar Akuntansi Adaptasi Indonesia, Buku 1, Salemba Empat, Jakarta.

Suprayitno, Eddy (2011), Perspektif Balanced Scorecard, diakses dari

http://ekonomi.kompasiana.c om, diunduh 3 Oktober 2015.

Wibowo, (2013), Manajemen Kinerja, Edisi 3, Cetakan 6, PT Rajagrafindo Persada, Jakarta.

http://www.jiscinfonet.ac.uk/infokits/ analytical-tools/scorecard 